\title{
Advance Research Directives in Germany
}

\section{A Proposal for a Disclosure Standard}

\author{
Matthé Scholten ${ }^{1 *}$, Astrid Gieselmann ${ }^{*}$, Jakov Gather ${ }^{1,2}$, and Jochen Vollmann ${ }^{1}$ \\ ${ }^{1}$ Institute for Medical Ethics and History of Medicine, Ruhr University, Bochum, Germany \\ ${ }^{2}$ Department of Psychiatry, Psychotherapy and Preventive Medicine, LWL University Hospital, Ruhr University, Bochum, Germany
}

\begin{abstract}
The fourth amendment to the German Medicinal Products Act (Arzneimittelgesetz) states that nontherapeutic research in incompetent populations is permissible under the condition that potential research participants expressly declare their wish to participate in scientific research in an advance research directive. This article explores the implementation of advance research directives in Germany against the background of the international legal and ethical framework for biomedical research. In particular, it addresses a practical problem that arises from the disclosure requirement for advance research directives. We show that, if the disclosure standard for advance research directives is set at a token level, nontherapeutic research in incompetent populations becomes practically impossible. To resolve this issue, we suggest the disclosure standard be set at a type level.
\end{abstract}

Keywords: advance research directives, research ethics, informed consent, competence, dementia

\section{Introduction}

The combination of an aging population with advances in healthcare means a large increase of persons with dementia in the coming decades. In 2015, there were 46.8 million persons with dementia worldwide, and this number is estimated to rise to 131.5 million persons in 2050 (Prince, Wimo, Guerchet, Ali, Wu, \& Prina, 2015). The most common cause of dementia is Alzheimer's disease. To date no treatment is able to stop the cognitive decline associated with Alzheimer's, let alone cure the disease (Cummings, Isaacson, Schmitt, \& Velting, 2015). Because of the burdens and hardships persons with dementia and their relatives face, it is widely held that there is an urgent need for biomedical research in this field (Alzheimer's Association, n.d.).

It is no less essential, however, that this research comply with ethical principles. A fundamental principle of research ethics is that potential research participants provide informed consent to their participation in the study (Beauchamp \& Childress, 2013). Furthermore, it is generally held that persons can provide valid consent to participation in a research study only if they are competent (Kim, 2010). Persons are competent to participate in a research study if - and only if - they are sufficiently able to understand the nature, methods, risks, and benefits of the research project, to appreciate the effects of research participation on their own situation, to process the disclosure information in a rational way, and to express a choice regarding their participation (Appelbaum \& Grisso, 2001; Appelbaum \& Roth, 1982).
Dementia is a syndrome that involves disturbances in multiple higher cortical functions, including memory, thinking, orientation, comprehension, calculation, learning capacity, language, and judgment (World Health Organization, 2016). Because of these cognitive symptoms, dementia is a risk factor for incompetence (Kim, 2010). One study found that $70 \%$ of persons with Alzheimer's disease and 95\% of persons with scores below 18 on the Mini-Mental State Examination (MMSE) are either incompetent or only marginally competent to consent to their participation in research studies (Pucci, Belardinelli, Borsetti, Rodriguez, \& Signorino, 2001). Another study conducted in the UK found that, according to the relevant legal criteria, $76 \%$ of persons with mild to moderate dementia are incompetent to consent to research participation (Warner, McCarney, Griffin, Hill, \& Fisher, 2008).

This creates a moral dilemma. On the one hand, there is a moral imperative to conduct dementia research to alleviate the burdens of dementia; on the other hand, it seems morally impermissible to include incompetent persons in this type of research.

Advance research directives (ARDs) were proposed as a possible solution to this dilemma (Berghmans, 1998; Buller, 2015; Jongsma, 2016; Moorehouse \& Weisstub, 1996; Pierce, 2010). ARDs are written documents that enable competent persons to express their preferences regarding research participation for situations of future incompetence. The thought is that ARDs make it possible to include incompetent persons in biomedical studies on ethically justifiable grounds. On the other hand, ethical and practical concerns have been raised regarding the implementation of ARDs (Dresser, 1999; 2000).

* Matthé Scholten and Astrid Gieselmann contributed equally to this work. 
ARDs are typically discussed as a tool warranting the inclusion of incompetent persons in nontherapeutic research involving more than minimal risks and burdens. A research study is called "nontherapeutic" when the expected direct benefits to research participants do not outweigh the risks and burdens of research participation (Council for International Organizations of Medical Sciences [CIOMS], 2016). A research study is said to involve more than "minimal risks" and "minimal burdens" when the risks and burdens of research participation exceed the risks and burdens encountered in daily life or during routine physical or psychological examinations (CIOMS, 2016).

Under a number of strict conditions, the international legal and ethical framework allows for nontherapeutic research involving only minimal risks and minimal burdens in incompetent populations. Partly because of its history of large-scale abuse in biomedical research during the Nazi period, such research is prohibited in Germany. This will change when the fourth amendment to the German Medicinal Products Act (Arzneimittelgesetz, AMG) takes effect. In addition to the strict requirements imposed by the international framework, the AMG rules that incompetent persons can be included in nontherapeutic research only if they have expressly declared their wish to participate in such research in an ARD.

This paper explores the implementation of ARDs in Germany against the background of the international legal and ethical framework. It also addresses a practical problem that arises from the disclosure requirement for ARDs imposed by the AMG. To solve this problem, we propose an alternative disclosure standard.

The focus of this paper lies on persons with dementia and their inclusion in dementia research. Our statements about the criteria for nontherapeutic research in incompetent populations, however, hold for all types of research in incompetent persons - whatever the medical condition of these persons may be. Furthermore, ARDs can be a valuable tool for all persons with medical conditions involving temporary incompetence. Besides dementia, notable examples are schizophrenia, bipolar disorder, and depression. For reasons detailed further below, the practical challenge we address in this paper is typically found in the case of dementia.

The next section outlines the international framework for nontherapeutic research in incompetent populations. Thereafter, we define the requirements of ARDs and the accompanying disclosure requirement in the AMG. We subsequently show that there are reasons to maintain a disclosure requirement for ARDs even if no such requirement exists for advance treatment directives (ATDs). The disclosure standard for ARDs can be set at what we propose to call a "token level" or a "type level": At a token level, persons who complete an ARD must be informed about the aims, methods, risks, and burdens of the specific trial in which they want to participate; at a type level, these persons must be informed about the general aims, methods, risks, and burdens of the types of nontherapeutic research studies that can be conducted in incompetent populations. In the final section, we show that, if the disclosure standard for ARDs is set at a token level, nontherapeutic research in incompetent populations becomes practically impossible. To resolve this issue, we suggest that the disclosure standard be set at a type level.

\section{Nontherapeutic Research in Incompetent Populations: The International Framework}

Informed consent is typically a necessary condition for participation in biomedical research. Some international human rights documents and ethical guidelines understand this requirement as an absolute condition. Article 7 of the International Covenant on Civil and Political Rights and article 15(1) of the Convention on the Rights of Persons with Disabilities, for example, state that "no one shall be subjected without his free consent to medical or scientific experimentation." Similarly, in its first article the Nuremberg Code declares that, for participation in biomedical research, "the voluntary consent of the human subject is absolutely essential." Since persons must be competent for their consent to be valid, the absolute requirement of actual consent logically excludes incompetent persons from participation in biomedical research altogether.

Nowadays, this complete exclusion of incompetent persons is seen as unjust. This is most obvious in the case of therapeutic research. No established curative therapies are available for many diseases and medical conditions. Biomedical research is considered therapeutic when the ratio of expected benefits and burdens of research participation is more favorable than any of the established treatment alternatives. Excluding incompetent persons from participation in biomedical research obviously aims to protect these persons from the risks of research participation. Excluding incompetent persons from therapeutic research, however, in fact exposes these persons to greater risks, inasmuch as they are deprived of the medical intervention with the most favorable ratio of expected benefits and burdens. For example, if a person with moderate dementia suffers from considerable side effects of the approved types of medication for memory loss, it may be beneficial to that person to be included in a study on a medicament that promises less severe side effects.

Somewhat different considerations hold for nontherapeutic research. The exclusion of incompetent persons from biomedical research has resulted in a small evidence base for potential treatments of conditions such as Alzheimer's disease. Biomedical research could likely have benefited many persons with such conditions, had it been permitted to conduct minimal risk research in incompetent populations. If so, the exclusion of incompetent persons from participation in nontherapeutic re- 
Table 1. International legal documents and ethical guidelines for biomedical research

\begin{tabular}{|c|c|c|}
\hline Year & Organization & Name \\
\hline 1947 & & The Nuremberg Code \\
\hline 1997 & Committee of Ministers of the Council of Europe & $\begin{array}{l}\text { Convention for the Protection of Human Rights and Dignity of the } \\
\text { Human Being with Regard to the Application of Biology and Medi- } \\
\text { cine: Convention on Human Rights and Biomedicine (Oviedo Conven- } \\
\text { tion) }\end{array}$ \\
\hline 2005 & $\begin{array}{l}\text { United Nations Educational, Scientific and Cultural Organization } \\
\text { (UNESCO) }\end{array}$ & Universal Declaration on Bioethics and Human Rights \\
\hline 2013 & World Medical Association (WMA) & $\begin{array}{l}\text { Declaration of Helsinki - Ethical Principles for Medical Research In- } \\
\text { volving Human Subjects }\end{array}$ \\
\hline 2014 & The European Parliament and the Counsel of the European Union & $\begin{array}{l}\text { Regulation (EU) No 536/2014 on Clinical Trials on Medicinal Prod- } \\
\text { ucts for Human Use }\end{array}$ \\
\hline 2016 & Council for International Organizations of Medical Sciences (CIOMS) & $\begin{array}{l}\text { International Guidelines for Health-Related Research Involving Hu- } \\
\text { mans }\end{array}$ \\
\hline 2016 & $\begin{array}{l}\text { International Council for Harmonisation of Technical Requirements } \\
\text { for Pharmaceuticals for Human Use }(\mathrm{ICH})\end{array}$ & ICH Guideline for Good Clinical Practice E6(R2) \\
\hline
\end{tabular}

search entails an unjust distribution of the benefits and burdens of biomedical research.

For these reasons, the international framework allows for nontherapeutic research with incompetent persons, albeit under a number of strict conditions. Table 1 provides an overview of the relevant legal documents and ethical guidelines.

Traditionally, nontherapeutic research with incompetent persons was permitted only exceptionally and with special justification. Recent guidelines, however, shift the burden of proof: Guideline 16 of the CIOMS Guidelines, for example, states that "adults who are not capable of giving informed consent must be included in health-related research unless a good scientific reason justifies their exclusion."

This change in direction does not imply that less strict conditions would apply for nontherapeutic research in incompetent populations. Although the precise formulations of the safeguards differ somewhat, one can distill the following necessary conditions for nontherapeutic biomedical research in incompetent populations from the documents contained in Table 1 (setting aside the Nuremberg Code):

Nontherapeutic biomedical research with an incompetent person is permissible only if,

1. Consent is given by a legally authorized representative.

2. The research participants are involved in the decision-making process at the level of their ability.

3. The research participant's assent to research participation is sought insofar as the person is able to provide such assent.

4. The research participant does not expressly dissent to research participation.

5. The research is intended to promote the health of persons with the same medical condition as the research participant ("principle of group benefit").

6 . The data cannot be obtained by means of research with competent persons ("subsidiarity principle”).
7. The research involves only minimal risks and minimal burdens ("minimal risk standard").

It is important to note that, taken together, these necessary conditions are not sufficient to make nontherapeutic research with incompetent persons permissible. The research protocol and the informed consent process of a nontherapeutic research study in an incompetent population must satisfy all other conditions that apply to "ordinary" biomedical research as well.

The conditions require some elaboration. Conditions (1) to (4) concern the informed consent process and the decisionmaking process more broadly. The requirement of consent by a legally authorized representative in case of incompetence is familiar from the treatment context (Buchanan \& Brock, 1990). Most human rights documents and guidelines relating to biomedical research do not specify the grounds on which the legally authorized representative should base the decision regarding research participation, and the documents and guidelines that do specify these grounds seem to diverge somewhat. The Universal Declaration on Bioethics and Human Rights, for example, declares in Article 7(1) that "authorization for research and medical practice should be obtained in accordance with the best interest of the person concerned.” By contrast, Guideline 16 of the CIOMS Guidelines states that the consent of a legally authorized representative "takes account of the participant's previously formed preferences and values." We assume here that the legally authorized representative should base consent on the potential participant's previously formed preferences and values.

One could be inclined to think that, if a potential research participant is incompetent, their wishes and preferences regarding research participation may simply be disregarded in the decision-making process. Conditions (2) to (4) serve to counter this thought and to ensure that incompetent persons are involved in the decision-making process to the level of their ability. Incompetent persons, too, have an interest in making their 
own decisions. Thus, a study physician should disclose the relevant information to an incompetent research participant, and the disclosure information and the means of communication should be adapted to the research participant's abilities. Furthermore, the wishes and preferences of incompetent persons should be given seriously consideration in the process leading up to a proxy decision.

Potential research participants who lack the capacity to consent to research participation may still have the ability to assent or dissent to participation (Black, Brandt, Rabins, Samus, Steele, Lyketsos, et al., 2008). Although there is no consensus yet on what exactly counts as assent and dissent, they may be broadly defined as the verbal or nonverbal expression of the willingness/unwillingness to participate, respectively (Black, Rabins, Sugarman, \& Karlawish, 2010). Conditions (3) and (4) serve to ensure that the assent of the potential research participant is sought, and that any dissent is respected.

Conditions (5) to (7) concern the research protocol and the research process. In some cases biomedical research was performed on a group of persons with a certain medical or mental condition merely to obtain health benefits for the general population. The principle of group benefit expressed in condition (5) serves to rule out such exploitation and unfair distribution of the benefits and burdens of biomedical research at a group level. For nontherapeutic research with incompetent persons with, say, Alzheimer's disease to be permissible, the research must accordingly be aimed at improving potential treatments of Alzheimer's disease or gaining further insight into the nature or causes of the disease.

In the past, incompetent persons have sometimes been used as research subjects merely because they can be easily recruited and are less likely to file lawsuits. Historically, the subsidiarity principle expressed in condition (6) was introduced to rule out exploitation of the vulnerabilities of incompetent persons. But the principle is also relevant in cases that do not involve such blatant exploitation. Sometimes, the data necessary to promote the health of incompetent persons with a certain medical condition can be obtained by conducting research with competent persons. Suppose, for example, that the effects of a particular type of medication to reduce cognitive symptoms in moderate to late-stage dementia can be tested in persons with mild cognitive impairment or early-stage dementia (assuming that extrapolation is possible). If this is the case, the subsidiarity principle yields that the study may not be conducted in an incompetent population.

The minimal risk standard expressed in condition (7) stipulates that nontherapeutic research with incompetent persons may involve only minimal risks and minimal burdens, whereby risks and burdens are not identical: Risks refer to the potential consequences of the interventions that participants undergo during the research process, whereas burdens refer to the inconveniences those interventions already involve, regardless of their consequences (CIOMS, 2016). Thus, lumbar puncture with general anesthesia involves smaller burdens but larger risks than lumbar puncture without general anesthesia. Furthermore, it is important to bear in mind that risks are defined by the magnitude of the potential harm multiplied by the probability of the potential harm.

Risks and burdens are typically considered to be minimal if they do not exceed the risks and burdens encountered in ordinary life or during routine physical or psychological examinations (CIOMS, 2016). Since this is only a loose definition, narrower determination must be made by institutional review boards. The commentary to Guideline 4 of the CIOMS Guidelines furthermore warns that research participants may not be exposed to greater risks and burdens merely because they face greater risks and burdens in everyday life on account of being poor or belonging to some disadvantaged group.

\section{The Fourth Amendment of the German Medicinal Products Act (Arzneimittelgesetz, AMG)}

The fourth amendment to the German Medicinal Products Act (Arzneimittelgesetz, AMG) permits nontherapeutic biomedical research in incompetent populations in Germany under a number of strict conditions. The amendment was adopted by the German Federal Diet (Bundestag) on the 11 November 2016.

The AMG was prompted by the adoption of EU Regulation No. 536/2014 on clinical trials on medicinal products for human use. The EU Regulation entered into force in 2014 and is expected to take effect in 2019. Like the documents reviewed in the previous section, the EU Regulation permits nontherapeutic research with incompetent persons under a number of strict conditions. Although EU law is binding on member states, Germany was not bound by the EU Regulation to update the AMG: Article 31.1 of the EU Regulation states that, with regard to nontherapeutic research studies, it is "without prejudice to more stringent national rules prohibiting the conduct of those clinical trials on incapacitated subjects.” Nonetheless, the EU Regulation prompted the German Diet to harmonize its national rules with the international framework.

Adoption of the AMG was preceded by an intense public and academic debate (Dabrock, 2016; Jox, Spickhoff, \& Marckmann, 2017; Lob-Hüdepohl, 2016; Marckmann \& Pollmächer, 2017; Schneider, 2016; Taupitz, 2016). The central question at issue in this debate was whether it is ever permissible to conduct nontherapeutic research in incompetent populations. The outcome of these discussions was that this type of research should indeed be permissible under a number of strict conditions.

$\S 40 \mathrm{~b}(4.1)$ of the AMG stipulates that nontherapeutic research with incompetent persons is permissible only if the conditions set out in Articles 31.1 and 31.3 of the EU Regulation are satisfied. Apart from the seven conditions mentioned in the 
previous section, Article 31.1(3) of the EU Regulation explicitly adds that the legally authorized representative may not be offered compensation other than reimbursement for direct or indirect expenses. This condition is intended to decrease the likelihood that the legally authorized representative is subject to undue influence or decides on any grounds other than the previously expressed preferences and values of the potential research participant. In view of this, it is plausible to assume that the condition is implicit in the other documents as well. We shall, therefore, not include it as a separate condition.

To reach an accommodation between the proponents and opponents of the proposal to permit nontherapeutic research in incompetent populations, the German Federal Diet settled on an additional safeguard for research participation of incompetent persons: Besides the seven conditions mentioned in the previous section, $\$ 40 \mathrm{~b}(4)$ of the AMG requires that incompetent research participants have declared their wish to participate in a nontherapeutic research study in a research advance directive (ARD). To the list of conditions for nontherapeutic research in incompetent populations, we can accordingly add the following condition:

8. The research participant has declared her wish to participate in scientific research in a valid ARD.

Recall that ARDs were discussed in the context of biomedical studies involving more than minimal risks and minimal burdens, and hence as a tool that could warrant biomedical research not yet possible under the international framework. By contrast, the AMG introduces ARDs only as an additional safeguard: The ARD requirement must be satisfied in addition to the other requirements for nontherapeutic research in incompetent populations, such as the minimal risk standard.

What are the grounds for adding such an additional safeguard? The motivation lies in problems regarding proxy consent (i.e., consent by a formal or informal representative). A systematic review of empirical studies showed that, on average, proxy decision-makers incorrectly predict the end-of-life treatment preferences of patients in $32 \%$ of cases (Shalowitz, Garrett-Mayer, \& Wendler, 2006). Since persons are less likely to discuss their preferences regarding research participation than their preferences regarding end-of-life care with their relatives and friends, it can be expected that the accuracy of proxy decisions regarding research participation will be even lower.

For these and other reasons, some have argued that incompetent persons must have an ARD if they are to participate in nontherapeutic biomedical research (Warner \& Nomani, 2008). ARDs have several advantages over proxy consent. First, whereas proxy decision-makers must base their decisions on their necessarily limited knowledge of the potential participants' values and preferences, with ARDs the potential research participants themselves have declared whether (or not) they want to participate in research. Therefore, it is expected that ARDs more accurately reflect the potential participant's preferences than do proxy decisions. Second, being asked to complete an ARD prompts persons to deliberate whether or not they would want to participate in research and the ARD documents the outcome of the deliberative process.

On the other hand, it can be argued that the inaccuracy of proxy decisions is not decisive. An interview study and a survey study conducted in the United States showed that most members of the general public were in fact willing to allow a proxy decision-maker to make decisions regarding research participation. Furthermore, a majority was willing to grant the proxy decision-maker significant leeway (Karlawish, Rubright, Casarett, Cary, ten Have, \& Sankar, 2009; Kim, Kim, Langa, Karlawish, Knopman, \& Appelbaum, 2009). In addition, the completion rate of ARDs will expectably be low. In one study, a great majority of persons who expressed both a willingness to participate in nontherapeutic research when they are incompetent and a willingness to complete an ARD did in fact not complete one (Wendler, Martinez, Fairclough, Sunderland, \& Emanuel, 2002). This suggests that the ARD requirement poses an obstacle to nontherapeutic minimal risk research in incompetent populations. Since most persons endorse proxy consent and are willing to grant proxy decision-makers significant leeway, the requirement seems unnecessarily restrictive.

In the end, the German Federal Diet decided in favor of an ARD requirement. When introducing the requirement in $\S 40 \mathrm{~b}(4)$, the AMG refers to the so-called Law on Advance Directives, present in $\$ 1901$ a of the German Civil Code (Bürgerliches Gesetzbuch), which regulates Advance Treatment Directives (Patientenverfügungen, ATDs). The AMG's reference to the Law on Advance Directives means that the criteria for the validity and efficacy of ATDs equally apply to ARDs.

According to the German Law on Advance Directives, an ATD is valid if - and only if - the person who completes the ATD was competent and of legal age at the time of completing the document, the ATD is available in written form and signed by the person who completed it, and the medical condition and the treatment situation delineated in the ATD match the person's actual medical condition and the actual treatment situation.

Further requirements for the validity of ATDs were discussed during the parliamentary process but were not included in the law. Notarization and regular updating, to mention but two examples, are not required for the validity of ARDs. More important for our aims, the German law on advance directives does not contain a disclosure requirement for ATDs. Accordingly, an ATD can be binding even if the relevant information about treatment alternatives was not previously disclosed to the person by a physician.

Here, one can observe an important contrast between the law on advance directives in the German Civil Code and the ARD requirement in the AMG. Whereas §1901a of the Civil Code includes no disclosure requirement for ATDs, $\$ 40 \mathrm{~b}(4)$ of the AMG explicitly states that the person who completes an ARD "must be informed about all the details that are essential for the consent." In particular, the person must be informed 
about "the nature, objectives, benefits, implications, risks, and inconveniences of clinical trials that are conducted under the conditions of article 31 of the EU Regulation.”

This passage seems to leave some interpretative leeway regarding the level of specificity of the disclosure. The relevant passage refers to "clinical trials" (in the plural) conducted under the conditions of Article 31 of the EU Regulation. In view of this, the disclosure requirement could be interpreted as saying that, for an ARD to be valid, the potential research participant must have been informed about the general aims, methods, risks and burdens of the types of nontherapeutic research studies that can be conducted in incompetent populations. We propose to call this disclosure standard "type-disclosure." More commonly, however, the disclosure requirement is understood to say that, for an ARD to be valid, the potential research participant must have been informed about the aims, methods, risks and burdens of the specific trial in which she wants to participate (Marckmann \& Pollmächer, 2017). We propose to call this disclosure standard "token-disclosure."

\section{Reasons for Maintaining a Disclosure Requirement for Advance Research Directives}

The requirement of token-disclosure for ARDs presents an insurmountable obstacle to nontherapeutic research in incompetent populations. In the previous section, we already mentioned that the completion rate of ARDs will expectably be low. This presents a major but not an insurmountable hurdle to scientific research that is generally deemed morally desirable. If the disclosure standard for ARDs is set at a token level, however, nontherapeutic research in incompetent populations becomes practically impossible.

The reasons are as follows. Recall that an ARD is valid only if it is completed by a competent person. Completing an advance directive requires quite complex cognitive abilities (Silberfeld, Nash, \& Singer, 1993). Since the cognitive decline in dementia proceeds gradually over the course of several years, ARDs must therefore typically be written years before the research study is conducted - at which point of time the details of the research protocol of the research study in which the person would participate will not yet be available. Accordingly, if token-disclosure is required for ARDs, it becomes practically impossible to include incompetent persons with dementia in nontherapeutic research.

This exposes an inherent tension in the AMG. The AMG permits nontherapeutic research in incompetent populations (arguably because such research is morally desirable), while at the same time ruling out the possibility of such research by including an unreasonably high standard for disclosure for ARDs.

One way to resolve this tension is to drop the disclosure requirement for ARDs. Indeed, one could argue that the disclosure requirement for ARDs contained in the AMG is inconsistent with the absence of such a requirement for ATDs in the German Civil Code. This asymmetry is unjustified, some scholars have argued, given that the risks involved in refusing lifeprolonging treatment in an ATD are much higher than the risks involved in consenting to minimal risk studies in an ARD (Jox, Spickhoff, \& Marckmann, 2017; Marckmann \& Pollmächer, 2017).

There might, however, be reasons for the asymmetry. First of all, ATDs are typically used to enunciate treatment refusals. In daily care situations, competent adults are normally allowed to refuse treatment even if they are not informed about the nature, meaning, and implications of the various treatment alternatives. The legislator's reluctance to include a disclosure requirement for ATDs seems appropriate in this light.

What, then, could be the reasons for introducing a disclosure requirement for ARDs? Several morally relevant differences between the treatment and the research context must be taken into account. First, the constellation of interests in the research context differs from that found in the treatment context. To put it bluntly, treating physicians are primarily interested in helping their patients, whereas scientists are primarily interested in generating generalizable and reliable data (and publishing them in high-ranked journals). For this reason, it could be argued that consent to research participation should be subject to additional requirements to protect research subjects from abuse and exploitation. The disclosure requirement for ARDs can function as one of these safeguards.

Second, it seems mistaken to assume that the risks involved in refusing life-prolonging treatment in an ATD are necessarily higher than the risks involved in consenting to minimal-risk studies in an ARD. A risk is defined by the magnitude of the potential harm multiplied by the probability of the harm. Whether a particular event qualifies as a harm depends in part on the preferences of the person concerned. If a person refuses life-sustaining treatment in a particular treatment situation, this indicates that this person would rather die than go on living, given the expected consequences of the available treatment alternatives. In such cases, death should not be considered a harm. Consequently, the occurrence of death as a consequence of a treatment refusal is typically not a risk.

By definition, nontherapeutic research studies have a negative ratio of expected risks and benefits. Indeed, incurring a peripheral nerve injury after venipuncture constitutes a harm to a person even if that person wishes to participate in a research study involving blood draws. The risks involved in consenting to nontherapeutic studies may accordingly be higher than the risks involved in refusing life-prolonging treatment. This, in turn, could speak in favor of maintaining the asymmetry between ATDs and ARDs regarding the disclosure requirement.

Third, the right to refuse treatment is a (negative) claim right, while the right to participate in biomedical research is 
a liberty right. The Hohfeldian analysis of rights is particularly helpful here (Hohfeld, 1917). According to this analysis, one has a negative claim right just in case others have a duty not to interfere. Thus, I have a negative claim right that others do not enter my house without my permission just in case others have a duty not to enter my house without my permission. The picture is different with liberty rights. According to the Hohfeldian analysis, a person has a liberty right to perform some action just in case she does not have a duty to refrain from performing that action. By asserting a liberty right, however, one does not impose a duty on others. For example, I may have a liberty right to buy a famous painting at an auction (and hence not be under an obligation to refrain from buying the painting), but that does not mean that other persons present at the auction are under an obligation to refrain from buying the painting.

All of which has the following implications: When competent adults assert their negative claim right to refuse treatment in an ATD, they are putting the treating physician under an obligation to respect their refusal. By contrast, when competent adults assert their liberty right to participate in biomedical research, they do not put scientists under an obligation to include them in a research study. The alternative to respecting a treatment refusal expressed in a valid ATD consequently involves doing something that is at least prima facie impermissible (i.e., treating people against their will). But the alternative to respecting a person's consent to research participation expressed in a valid ARD does not involve doing something that is impermissible (because scientists are at liberty to refrain from including persons in their study at their discretion). This seems to count in favor of the asymmetry between ARDs and ATDs regarding the disclosure requirement.

We take no stance on whether these reasons are conclusive. Rather, we simply want to note that there are reasons that speak in favor of the asymmetry. Regardless of whether a disclosure requirement for ARDs is desirable from an ethical perspective, the AMG explicitly pronounces a disclosure requirement - and this is surely not an unintended result of the democratic process that preceded the amendment. We should, therefore, investigate whether the inherent tension in the AMG between warranting and frustrating nontherapeutic research in incompetent populations can be resolved in another way.

\section{A Proposal for a Disclosure Standard for Advance Research Directives}

An alternative to dropping the disclosure requirement for ARDs would be to adjust the standard of disclosure. Our pro- posal is to adjust the standard from token-disclosure to typedisclosure. According to this proposal, persons who want to complete an ARD must be informed about the various types of minimal risk studies rather than about the details of a particular study. Consequently, persons declare in an ARD that they are willing to participate in certain types of research rather than in specific studies. The task of the legally authorized representative then is to assess whether the particular study at hand falls under the types of research delineated in the ARD, and whether participation in the study is compatible with the potential participant's previously expressed values and preferences.

Nontherapeutic research in incompetent populations is subject to the minimal risk standard. Since the number of measures and methods possible under these constraints is limited, it is possible to develop a taxonomy of the possible types of minimal risk research. It would go too far to develop such a taxonomy within the limits of this paper, but the following examples of interventions involving minimal risks and minimal burdens should suffice to give a rough impression:

- general clinical observations

- physical examinations, e.g., measuring, weighing, auscultation, or taking blood pressure

- collection of samples via noninvasive means, e.g., collection of hair, saliva samples, or other swabs

- noninvasive diagnostic measures, e.g., ECG or EEG

- diagnostic imaging, e.g., ultrasound or (limited) x-rays

- collection of blood samples, e.g., obtained by a central line already in place or by means of (limited) peripheral venipunctures (controversial)

- neuropsychological screening, e.g., MMSE or mini-cog

- social science research, e.g., surveys, interviews, or qualitative observational studies.

Some of these interventions may not seem directly relevant to the established types of dementia research. Our aim, however, is merely to list a few interventions that would count as involving minimal risks and minimal burdens. Clearly, these interventions satisfy the minimal risk standard only if the number of interventions is kept small and the methods used are not incriminating.

Setting the disclosure standard for ARDs at a type level has several advantages, the most important of which is that the practical impossibility of having to consent to a nonexistent research protocol disappears. But the adjustment has several other advantages as well. Since the number of possible minimal risk studies is limited, it will be possible to develop standardized disclosure material. This makes it possible to test empirically whether this material forges a sufficient level of understanding in persons who want to complete an ARD. In order to improve the quality of the disclosure, study physicians can be trained in using the standardized disclosure material, and targeted methods for supported decision-making, such as enhanced consent procedures, can be developed. These methods have proved to 
be effective in enhancing understanding in the research informed consent process (Nishimura, Carey, Erwin, Tilburt, Murad, \& McCormick, 2013).

Furthermore, established methods for advance care planning could be adapted to the research context to guide potential research participants in completing an ARD. Advance care planning enables patients to identify the values on which future decisions should be based, which improves the decision-making process (Coors, in der Schmitten, \& Jox, 2015; Detering, Hancock, Reade, \& Silvester, 2010). Such advance research planning would also provide potential research subjects with an opportunity to discuss their preferences regarding research participation with their proxy decision-makers, which will improve the proxy decision-maker's ability to abide by the potential research participant's preferences (Scholten \& Gather, 2018). Finally, by having standardized disclosure material at their disposal, dementia researchers can approach potential research participants proactively. In this way, the completion rate of ARDs can be increased.

Opponents of this proposal could object that type-disclosure does not meet the standard of disclosure ordinarily required for valid informed consent. To give actual consent to a clinical trial, potential research participants must understand the aims, methods, and expected consequences of the specific trial. In the previous section, we showed that requiring token-disclosure for ARDs makes nontherapeutic research in incompetent populations practically impossible. The outcome of the deliberative democratic process in Germany was that, if conducted under strict conditions, this type of research is morally desirable. In view of this, requiring token-disclosure for ARDs is problematic.

Our proposal also shows how ARDs can serve as an additional safeguard besides the requirement of consent by a legally authorized representative. If the disclosure standard for ARDs is set at a token level, the role of the legally authorized representative in the informed consent process is unclear. After all, it is widely accepted that advance directives are binding without the consent of a proxy decision-maker or legally authorized representative. If the standard of disclosure is set at a token level, ARDs thus replace rather than complement consent by a legally authorized representative.

If, by contrast, the standard is set at a type level, the legally authorized representative has a clear complementary role. Whereas the ARD articulates in what types of research the person wants to participate, the legally authorized representative is responsible for assessing whether the study at hand falls under the types of research delineated in the ARD and whether participation in the study is compatible with the person's previously expressed values and preferences. In this way, ARDs would genuinely be complementary to the consent of a legally authorized representative.

\section{Conclusion}

The fourth amendment to the German Medicinal Products Act (Arzneimittelgesetz) rules that nontherapeutic research in incompetent populations is permissible only if potential research participants have declared their wish to participate in research in an ARD. Furthermore, the AMG states that persons who want to complete an ARD must be informed about the circumstances of research participation.

We take no stance on whether ARDs are required to make nontherapeutic research in incompetent populations ethically justifiable or on whether ARDs should be subject to a disclosure requirement. Starting from the assumption that the AMG specifies both an ARD requirement for this type of research and a disclosure requirement for ARDs, we have shown that, if the disclosure standard is set at a token level, the AMG makes nontherapeutic research in incompetent populations practically impossible. Consequently, the AMG warrants and at the same time hinders this type of research. We demonstrated that this tension can be resolved by setting the disclosure standard at a type level.

Further empirical research must be conducted to determine whether type-disclosure is preferable to token-disclosure. Most importantly, it is necessary to explore the views of potential research participants on the appropriate standard of disclosure for ARDs: Would they want to know all the relevant details about a specific study or would they be satisfied with more general information regarding the types of nontherapeutic studies in incompetent populations that are possible under German law?

Above, we noted that the disclosure requirement for ARDs in the AMG leaves some interpretative leeway regarding the specificity of the disclosure. In view of this, our proposal might be compatible with the new regulation. Should it turn out that only token-disclosure is compatible with the AMG, we recommend that the disclosure requirement for ARDs be amended.

\section{Acknowledgments}

This research is part of the international and interdisciplinary project ENSURE (2016-2019) and is supported by a grant from the German Federal Ministry of Education and Research (grant number 01GP1623B).

\section{Declaration of Conflicts of Interests}

The authors declare that no conflicts of interest exist. 


\section{References}

Alzheimer's Association. (n.d.). Medications for memory loss. Retrieved from https://www.alz.org/alzheimers_disease_standard_prescriptions.asp\#treatments

Appelbaum, P.S., \& Grisso, T. (2001). MacArthur competence assessment tool for clinical research (MacCAT-CR). Sarasota, FL: Professional Resource Press.

Appelbaum, P. S., Roth, L. H. (1982). Competency to consent to research: A psychiatric overview. Archives of General Psychiatry. 39, 951-958.

Berghmans, R. L. (1998). Advance directives for nontherapeutic dementia research: Some ethical and policy considerations. Journal of Medical Ethics, 24(1), 32-37.

Black, B. S., Brandt, J., Rabins, P. V., Samus, Q. M., Steele, C. D., Lyketsos, C. G., \& Rosenblatt, A. (2008). Predictors of providing informed consent or assent for research participation in assisted living residents. The American Journal of Geriatric Psychiatry, 16(1), 83-91.

Black, B. S., Rabins, P. V., Sugarman, J., \& Karlawish, J. H. (2010). Seeking assent and respecting dissent in dementia research. The American Journal of Geriatric Psychiatry, 18(1), 77-85.

Buchanan, A. E., \& Brock, D. W. (1990). Deciding for others: The ethics of surrogate decision making. Cambridge: Cambridge University Press.

Beauchamp, T. L., \& Childress, J.F. (2013). Principles of biomedical ethics (7th ed.). Oxford: Oxford University Press.

Buller, T. (2015). Advance consent, critical interests and dementia research. Journal of Medical Ethics, 41, 701-707.

Convention for the Protection of Human Rights and Dignity of the Human Being with Regard to the Application of Biology and Medicine: Convention on Human Rights and Biomedicine, Committee of Ministers of the Council of Europe. (1997). Retrieved from https://rm.coe.int/168007cf98

Convention on the Rights of Persons with Disabilities, United Nations. (2006). Retrieved from https://www.un.org/development/desa/disabilities/convention-on-the-rights-o f-personswith-disabilities.html

Coors, M., Schmitten, J. in der, \& Jox, R. (2015). Advance care planning. Stuttgart: Kohlhammer.

Council for International Organizations of Medical Sciences. (2016). International guidelines for health-related research involving humans. Retrieved from https://cioms.ch/wp-content/uploads/2017/01/WEB-CIOMS-EthicalGuidelines.pdf

Cummings, J.L., Isaacson, R.S., Schmitt, F.A., \& Velting, D. M. (2015). A practical algorithm for managing Alzheimer's disease: What, when, and why? Annals of Clinical and Translational Neurology, 2, 307-323.

Dabrock, P. (2016). Stellungnahme für die öffentliche Anhörung "Gruppennützige Forschung an nichteinwilligungsfähigen Menschen" des Gesundheitsausschusses des Deutschen Bundestages in Berlin am 19. Oktober 2016 [Statement for the public hearing on "nontherapeutic research with incompetent persons" by the Health Committee of the German Federal Diet in Berlin on October 19, 2016]. Retrieved from https://www.bundestag. de/blob/475632/1df6b67103a6a0539cc0ebc2883be71b/18_1 4_0210-1-_a mg_esv-dabrock-data.pdf

Detering, K. M., Hancock, A. D., Reade, M. C., \& Silvester, W. (2010). The impact of advance care planning on end of life care in elderly patients: Randomized controlled trial. British Medical Journal, 340, c1345.

Dresser, R. (1999). Planning for future research participation: Ethical and practical considerations. Accountability in Research, 7(2-4), 129-136.

Dresser, R. (2000). Advance research directives: Implementation issues. Journal of the American Geriatrics Society, 48, 859-860.
Hohfeld, W. N. (1917). Fundamental legal conceptions as applied in judicial reasoning. Faculty Scholarship Series Paper, 4378.

International Council for Harmonisation of Technical Requirements for Pharmaceuticals for Human Use. (2016). ICH guideline for good clinical practice E6(R2). Retrieved from http://www.ich.org/fileadmin/Public_Web_Site/ICH_Products/Guidelines/Efficacy/E6/E6 _R2__Step_4_2016_1109.pdf

International Covenant on Civil and Political Rights, United Nations. (1966). http://www.ohchr.org/EN/Professionallnterest/Pages/ CCPR.aspx

Jongsma, K. R. (2016). Advance directives in dementia research (Dissertation). Retrieved from http://www.persistent-identifier.nl/?identifier=urn:NBN:nl:ui:15-1765/79941

Jox, R.J., Spickhoff, A., \& Marckmann, G. (2017). Forschung mit nicht Einwilligungsfähigen: Nach dem Gesetz ist vor dem Gesetz [Research on incompetent persons: After one law comes the next law]. Deutsches Ärzteblatt, 114, A520-A523.

Karlawish, J., Rubright, J., Casarett, D., Cary, M., Have, T. ten, \& Sankar, P. (2009). Older adults' attitudes toward enrollment of noncompetent subjects participating in Alzheimer's research. The American Journal of Psychiatry, 166, 182-188.

Kim, S.Y.H. (2010). Evaluation of capacity to consent to treatment and research. Oxford: Oxford University Press.

Kim, S. Y. H., Kim, H. M., Langa, K. M., Karlawish, J. H. T., Knopman, D.S., \& Appelbaum, P.S. (2009). Surrogate consent for dementia research: A national survey of older Americans. Neurology, 72, 149-155.

Lob-Hüdepohl, A. (2016). Stellungnahme anlässlich der öffentlichen Anhörung im Ausschuss für Gesundheit des Deutschen Bundestages "Gruppennützige Forschung an nichteinwilligungsfähigen Erwachsenen" am 19. Oktober 2016 [Statement for the public hearing on "nontherapeutic research with incompetent persons" by the Health Committee of the German Federal Diet in Berlin on October 19, 2016]. Retrieved from https://www.bundestag.de/blob/475760/8b96b1f526e8d9667e9b951a061d97 89/18_14_0210-2-_a mg_esv-lob-huedepohl-data.pdf

Marckmann, G., \& Pollmächer, T. (2017). Ausschließlich gruppennützige Forschung mit nichteinwilligungsfähigen Menschen: Ein Kommentar zur Änderung des Arzneimittelgesetzes [Nontherapeutic research with incompetent persons: A commentary on the amendment of the Medicinal Products Act]. Der Nervenarzt, 88, 486-488.

Moorehouse, A., \& Weisstub, D. N. (1996). Advance Directives for research: Ethical problems and responses. International Journal of Law and Psychiatry, 19, 107-141.

Nishimura, A., Carey, J., Erwin, P. J., Tilburt, J. C., Murad, M. H., \& McCormick, J.B. (2013). Improving understanding in the research informed consent process: a systematic review of 54 interventions tested in randomized control trials. BMC Medical Ethics, 14, 28.

Pierce, R. (2010). A changing landscape for advance directives in dementia research. Social Science \& Medicine, 70, 623-630.

Prince, M., Wimo, A., Guerchet, M., Ali, G.-C., Wu, Y.-T., \& Prina, M. (2015). World Alzheimer report 2015: The global impact of dementia. Retrieved from https://www.alz.co.uk/research/worldreport-2015

Pucci, E., Belardinelli, N., Borsetti, G., Rodriguez, D., \& Signorino, M. (2001). Information and competency for consent to pharmacologic clinical trials in Alzheimer disease: An empirical analysis in patients and family caregivers. Alzheimer Disease and Associated Disorders, 15, 146-154.

Regulation (EU) No. 536/2014 on clinical trials on medicinal products for human use, The European Parliament and the Counsel of the European Union 2014. Retrieved from https://ec.europa. eu/health/human-use/clinical-trials/regulation_en

Schneider, F. (2016, November 9). Forschung an Demenzkranken möglich machen [Enabling research with persons with dementia]. Frankfurter Allgemeine Zeitung. 
Scholten, M., \& Gather, J. (2018). Adverse consequences of Article 12 of the UN Convention on the Rights of Persons with Disabilities for persons with mental disabilities and an alternative way forward. Journal of Medical Ethics, 44, 226-233. doi 10.1136/ medethics-2017-104414.

Shalowitz, D. I., Garrett-Mayer, E., \& Wendler, D. (2006). The accuracy of surrogate decision makers: A systematic review. Archives of Internal Medicine, 166, 493-497.

Silberfeld, M., Nash, C., \& Singer, P. A. (1993). Capacity to complete an advance directive. Journal of the American Geriatrics Society, 41, 1141-1143.

Taupitz, J. (2016). Stellungnahme zur Anhörung des Ausschusses für Gesundheit des Deutschen Bundestages zur gruppennützigen Forschung an nichteinwilligungsfähigen Menschen am 19. Oktober 2016 [Statement for the public hearing on "nontherapeutic research with incompetent persons" by the Health Committee of the German Federal Diet in Berlin on October 19, 2016]. Retrieved from https://www.bundestag.de/blob/475766/ab92dca9fdfa279eae 68298ce6d244f2/18_14_0210-4-_amg_es v-taupitz-data.pdf

The Nuremberg Code. (1947). In Trials of War Criminals before the Nuremberg Military Tribunals under Control Council Law, No. 10. Volume 2. Washington, DC: U.S. Government Printing Office, $181-182$.

Universal Declaration on Bioethics and Human Rights, United Nations Educational, Scientific and Cultural Organization (UNESCO). (2006). Retrieved from http://unesdoc.unesco.org/ images/0014/001461/146180E.pdf

Viertes Gesetz zur Änderung arzneimittelrechtlicher und anderer Vorschriften vom 20. Dezember 2016 [Fourth law for the amendment of legal regulations concerning medicinal products and other regulations of December 20, 2016]. 3048, Deutscher Bundestag 2016. Retrieved from https://www.bundesgesund- heitsministerium.de/ministerium/meldungen/2016/4-am gnovelle-verabschiedet/?L=0

Warner, J., McCarney, R., Griffin, M., Hill, K., \& Fisher, P. (2008). Participation in dementia research: Rates and correlates of capacity to give informed consent. Journal of Medical Ethics, 34, $167-170$.

Warner, J., \& Nomani, E. (2008). Giving consent in dementia research. The Lancet, 372(9634), 183-185.

Wendler, D., Martinez, R. A., Fairclough, D., Sunderland, T., \& Emanuel, E. (2002). Views of potential subjects toward proposed regulations for clinical research with adults unable to consent. The American Journal of Psychiatry, 159, 585-591.

World Health Organization. (2016). International Classification of Diseases: Mental and Behavioral Disorders (10th ed.). Geneva: Author.

World Medical Association. (2013). Declaration of Helsinki - Ethical principles for medical research involving human subjects. Retrieved from https://www.wma.net/policies-post/wma-declaration-of-helsinki-ethical-principles-for-medical-research-in volving-human-subjects/

Manuscript submitted: 24.01.2018

Manuscript accepted after revision: 24.02.2018

\section{Matthé Scholten}

Institute for Medical Ethics and History of Medicine

Ruhr University Bochum

Markstr. 258a

44799 Bochum

Germany

matthe.scholten@rub.de 